\title{
The Educational Potential of Teaching Science as Culture
}

\author{
Peter Heering ${ }^{1}$
}

Published online: 30 September 2016

(C) Springer Science+Business Media Dordrecht 2016

When looking at discussions about school education, there are two aspects which are striking with respect to science education: on the one hand, most authors (at least in Europe and North America) complain about the deficits in science education with respect to scientific literacy. Yet, despite the lamented quality, there seems to be hardly any doubt on whether science education is necessary as part of a general education.

When looking at the argumentation why science education is necessary (which is of course shaping the vision on how science education is to be improved), one finds basically two lines of argumentation. On the one hand, there is a position held most notably by politicians as well as by economists. At various occasions, they demanded an improvement of science education, most recently with the publication of results of assessments such as TIMSS or PISA. A central argument in this respect is the economic need of having sufficient scientific literate graduates-as a consequence, there will be sufficient scientists and engineers to ensure the national prosperity. At the same time, there are also complaints about the lack of sufficient numbers of qualified scientists and engineers that meet the needs of the commerce and thus challenge the economic future.

Taking these arguments seriously, science education should aim at providing more graduates who take a career in the sciences and engineering. Consequently, motivating more students to take science courses and enabling them to experience their self-efficacy in scientific contexts are relevant objectives. Even though I would not argue against these proposals, I doubt whether aiming just at improvements of this kind would be sufficient. To my understanding, general education should not be structured simply according to economic and employment requirements; consequently, it might be necessary to look for other perspectives.

Another argument that can be found frequently with respect to science education focuses on the necessity to have scientific literate citizens in a democratic society. This

Peter Heering

Peter.Heering@uni-flensburg.de

1 Institute of Mathematic, Scientific and Technical Literacy, Section of Physics, Its Didactics and Its History, Europa-Universität Flensburg, Auf dem Campus 1, 24943 Flensburg, Germany 
would include, e.g. their ability to assess evidence that is said to be scientific or to participate in (e.g. political or social) discussions about scientific or technological issues. Such literacy is connected with and can be achieved through an understanding of the nature of science. Consequently, school science education may aim at not just teaching science, but also at teaching about science. This should require a shift in focus from having more (and better) future scientists and engineers to having citizens who have a fundamental understanding about the sciences. Again, I would not argue against such an approach towards science education, yet, it still appears to miss one aspect that is relevant to me.

If we understand the purpose of school education as part of an enculturation, then we have to ask what is relevant with respect to our culture. Clearly, a number of school subjects come easily to one's mind, but in this respect, one should also identify the sciences as one of these subjects. Understanding science as the outcome of a cultural activity enables a broader legitimation of science education, it is no longer related to economic or societal needs but also to the ones of the individual. Such an understanding of science requires a broader approach in education. It is necessary to also take into consideration the historical, philosophical and sociological aspects, and to teach them as explicitly as the classical content of science such as plant growth, chemical reactions or basic laws in mechanics. Certainly, this needs to be done in an exemplary manner. Yet, by enabling students to understand both that science is affecting societal and cultural developments and that science is affected by societal and cultural development, they may come to different perspectives on sciences. From these perspectives, students may find individual access to sciences and to generate individual interests that are related to sciences.

We need to show students that science is not something outside of their daily experience, but a cultural activity, like writing, music and sports, and one that shapes and is shaped by the human world around them. Such an understanding of science (and science education) may be a first step to overcome the almost classical notion of 'two cultures'; it might also be an additional way to make science more meaningful. As a more than welcome 'by-product', students will be scientific literate, and-who knows-there thus might be even more students who can envision a career in the sciences and engineering. 